\title{
Preliminary Characterizations of a Carbohydrate from the Concentrated Culture Filtrate from Fusarium solani and Its Role in Benzo[a]Pyrene Solubilization
}

\author{
Etienne Veignie $^{1,2}$, Evgeny Vinogradov ${ }^{3}$, Irina Sadovskaya ${ }^{1,4}$, Charlène Coulon $^{1,4}$, Catherine Rafin ${ }^{12^{*}}$ \\ ${ }^{1}$ Univ Lille Nord de France, Lille, France \\ ${ }^{2}$ Université du Littoral Côte d'Opale, Unité de Chimie Environnementale et Interactions sur le Vivant (UCEIV), Dunkerque, France \\ ${ }^{3}$ Institute for Biological Sciences, National Research Council of Canada, Ottawa, Canada \\ ${ }^{4}$ Université du Littoral Côte d'Opale, Unité Mixte Technologique, Boulogne-sur-Mer, France \\ Email: ${ }^{*}$ rafin@univ-littoral.fr
}

Received July 1, 2012; revised August 1, 2012; accepted August 10, 2012

\begin{abstract}
In order to investigate the mechanism of benzo[a]pyrene uptake by a filamentous fungus Fusarium solani, a biochemical characterization of its concentrated culture filtrate has been conducted. The preparation contained approximately $(\mathrm{w} / \mathrm{w}): 50 \%$ of total carbohydrate, $6.5 \%$ of uronic acid and $6 \%$ protein, as determined by colorimetric tests. Gel filtration and anion-exchange chromatographic profiles indicated that the main product of the culture filtrate was a glycoprotein, which contained mannose, glucose and galactose in an approximate molar ratio of 1.5:0.8:1. The polysaccharide fraction of the culture filtrate was prepared by treatment with proteinase $\mathrm{K}$, followed by gel-filtration chromatography. Its chemical structure was studied by methylation analysis, gas-liquid chromatography-mass spectrometry (GC-MS) and Nuclear Magnetic Resonance spectroscopy (NMR). The major carbohydrate was a polymer of $\beta$ - $(1 \rightarrow 6)$-linked galactofuranose units fully branched at positions $\mathrm{O}-2$ by single residues of $\alpha$-glucopyranose. The Fusarium concentrated culture filtrate increased 4-fold the BaP solubilization in comparison with its aqueous solubility and suggested that the carbohydrate present in this filtrate should probably be involved in this enhancement. Our findings point out the potential role of fungal glycoproteins in PAH microbial bioavaibility, an important step for PAH biodegradation.
\end{abstract}

Keywords: Fusarium solani; Benzo[a]Pyrene; Polysaccharides; Glycoprotein; Nuclear Magnetic Resonance

\section{Introduction}

Polycyclic aromatic hydrocarbons (PAH) continuously entering the environment from natural sources (biogenic and geochemical) as well as anthropogenic ones are considered as priority pollutants due to their toxicity, mutagenic and carcinogenic properties [1]. Although PAH may undergo adsorption, volatilization, photolysis and chemical degradation, microbial degradation is the major degradation process [2]. The persistence of PAH in the environment is dependent on a variety of factors, such as their chemical structure, their concentration and their bioavailability. In general, the higher the molecular weight of the PAH, the lower its aqueous solubility, which limits the interaction of these compounds with microbial cells which principally use molecules that are dissolved in the water phase. Substrate bioavailability is therefore considered as one of the most important factors in bioremediation.

In a search for indigenous soil filamentous fungi with

"Corresponding author. potential to degrade $\mathrm{PAH}$ with four or more rings, our laboratory has isolated a collection of telluric fungi from PAH-contaminated soil [3-5]. We focused our attention on a Deuteromycete fungus Fusarium solani (Mart.) Sacc. (1881) [teleomorph: Haematonectria haematococca (Berk. and Broome) Samuels and Rossman, Ascomycota, Hypocreales, Nectriaceae] that was able to incorporate benzo[a]pyrene $(\mathrm{BaP})$ into small vesicles observed in fungal hyphae with high fluorescence due to accumulation of $\mathrm{BaP}$ or its metabolites $[3,6]$ before degradation and mineralisation $[7,8]$. This cytological observation underlines that this fungus has developed a strategy to enhance the bioavailability and gained access to hydrophobic compounds such as BaP. While numerous works concern the uptake of alkanes by fungi, and especially yeasts $[9,10]$, the mechanisms of PAH solubilization and transport were rarely studied in fungi $[6,11,12]$. In order to better understand the interaction mechanisms between the fungal cells and $\mathrm{PAH}$, we have undertaken the present investigation which reports the partial characterization of the concentrated fungal filtrate produced by the 
same Fusarium solani strain in liquid culture providing information on its chemical composition and on its properties to solubilize $\mathrm{BaP}$.

\section{Materials and Methods}

\subsection{Microorganism and Growth Conditions}

Fusarium solani previously isolated from petroleum-contaminated soil [3] was supplied from our UCEIV mycology collection (Dunkerque, France). Cultures were conducted in $300 \mathrm{ml}$ mineral salts medium (MM medium) containing $20 \mathrm{~g} \cdot \mathrm{l}^{-1}$ of glucose in 11 Erlenmeyer flasks. The standard mineral salts medium (MM) consisted of $\left(\mathrm{g} \cdot \mathrm{l}^{-1}\right): \mathrm{KCl}, 0.25 ; \mathrm{NaH}_{2} \mathrm{PO}_{4} 2 \mathrm{H}_{2} \mathrm{O}, 3.235 ; \mathrm{Na}_{2} \mathrm{HPO}_{4}$ $2 \mathrm{H}_{2} \mathrm{O}, 5.205 ; \mathrm{MgSO}_{4}, 0.244 ; \mathrm{NH}_{4} \mathrm{NO}_{3}, 2$; and traceelement solution consisting of $\left(\mathrm{mg} \cdot 1^{-1}\right): \mathrm{ZnSO}_{4} \cdot 7 \mathrm{H}_{2} \mathrm{O}, 1$; $\mathrm{MnCl}_{2} \cdot 4 \mathrm{H}_{2} \mathrm{O}, 0.1 ; \mathrm{FeSO}_{4} \cdot 7 \mathrm{H}_{2} \mathrm{O}, 1 ; \mathrm{CuSO}_{4} \cdot 5 \mathrm{H}_{2} \mathrm{O}, 0.5$; $\mathrm{CaCl}_{2} \cdot 2 \mathrm{H}_{2} \mathrm{O}, 0.1 ; \mathrm{MoO}_{3}, 0.2$. The culture medium was adjusted to $\mathrm{pH} 7$. After sterilization $\left(121^{\circ} \mathrm{C}\right.$ for $\left.20 \mathrm{~min}\right)$, inoculation was performed by adding a spore suspension of $F$. solani (aged 7 days), prepared as described previously [3], so as to obtain a final concentration of $10^{4}$ spores $\mathrm{ml}^{-1}$. After inoculation, Erlenmeyer flasks were incubated for 5 days at room temperature with shaking on a reciprocating shaker (Infors, Massy, France, $90 \mathrm{~min}^{-1}$ ).

\subsection{Preparation and Analysis of the Culture Filtrate}

After 5 days, hyphal fragments were removed by two filtrations through filter paper $(45 \mu \mathrm{m}$ and then $2.5 \mu \mathrm{m}$ filter). The culture filtrate was then lyophilized. The dry extract was dissolved in $25 \mathrm{ml}$ of deionized water, filtered through $2.5 \mu \mathrm{m}$ filter and dialyzed through a membrane (Difco, 12,000 to 14,000 Daltons) against deionized water at $4^{\circ} \mathrm{C}$ for 3 days (with changing water every $12 \mathrm{~h}$ ) and lyophilized, giving the concentrated culture filtrate. This crude culture filtrate was further fractionated by gelfiltration chromatography on Sephadex G-50 and Sephacryl S-200 columns, by ion-exchange chromatography on QSepharose, and analyzed by SDS-PAGE.

\subsection{Preparation and Structural Elucidation of the Polysaccharide}

The concentrated culture filtrate was dissolved in water and digested with proteinase $\mathrm{K}$ (Sigma, $2 \mathrm{mg} \cdot \mathrm{ml}^{-1}$ ) at $40^{\circ} \mathrm{C}$ for $24 \mathrm{~h}$. The digest was then fractionated by gelfiltration chromatography on a Sephadex G-50 column $(2.5 \times 60 \mathrm{~cm})$. The main peaks were collected and analyzed by composition analysis, methylation analysis and NMR spectroscopy.

\subsection{General and Analytical Methods}

Alditol acetates and partially methylated alditol acetates were analyzed by GC-MS on Varian Saturn 2000 system, equipped with DB-17 (30 m $\times 0.25 \mathrm{~mm})$ fused-silica column using a temperature gradient of 180 (2 $\mathrm{min})$ $\rightarrow 240^{\circ} \mathrm{C}$ at $2^{\circ} \mathrm{C} / \mathrm{min}$, with ion-trap mass spectral detector. Prior to analysis, samples were hydrolyzed with $4 \mathrm{M}$ TFA $\left(120^{\circ} \mathrm{C}, 3 \mathrm{~h}\right)$ and converted to alditol acetates by conventional methods. Methylation analysis was performed using the method previously described [13].

Gel-permeation chromatography was carried out on Sephadex G-50 columns $(1.6 \times 100 \mathrm{~cm}$ and $2.5 \times 60 \mathrm{~cm}$; GE Helthcare), irrigated with $1 \%$ acetic acid $-0.4 \%$ pyridine buffer. Ion-exchange chromatography was performed on a Q-Sepharose fast flow column $(1 \times 10 \mathrm{~cm}$, GE Healthcare) eluted with water followed by a $60 \mathrm{ml}$ linear gradient of aqueous $\mathrm{NaCl}(0-0.5 \mathrm{M})$. An aliquot of each fraction was assayed colorimetrically for aldose [14], uronic acid [15], and protein. Protein content was assayed by screening the fractions at $\mathrm{OD}_{280}$ or by BioRad colorimetric assay. D-Glucose (Glc, Sigma), D-glucuronic acid (GlcA, Sigma) and bovine serum albumin (BSA, Acros Organic) were used as standards.

SDS-PAGE was performed using a Bio-Rad Protean I system according to the method previously described [16] with $12 \%$ separating gel and $4 \%$ stacking gel. Gels were visualized with Coomassie blue stain for proteins and alcian blue/silver stain [17] for glycoproteins.

${ }^{1} \mathrm{H}$ and ${ }^{13} \mathrm{C}$ NMR spectra were recorded using a Varian Inova $500 \mathrm{MHz}$ spectrometer for samples in $\mathrm{D}_{2} \mathrm{O}$ solutions at $25^{\circ} \mathrm{C}-45^{\circ} \mathrm{C}$ with acetone internal reference $(2.23$ ppm for ${ }^{1} \mathrm{H}$ and 31.5 ppm for ${ }^{13} \mathrm{C}$ ) using standard pulse sequences DQCOSY, TOCSY (mixing time $120 \mathrm{~ms}$ ), NOESY (mixing time $400 \mathrm{~ms}$ ), HSQC and HMBC (100 ms long range transfer delay). ${ }^{1} \mathrm{H}_{-}{ }^{31} \mathrm{P} \mathrm{HMQC}$ and $\mathrm{HMQC}-$ TOCSY were run with ${ }^{1} \mathrm{H}_{-}{ }^{31} \mathrm{P}$ coupling set to $11 \mathrm{~Hz}$, TOCSY mixing time $100 \mathrm{~ms}$.

\subsection{BaP Solubilization}

$\mathrm{BaP}$ was initially dissolved in methanol $\mathrm{MeOH}(40$ $\mathrm{mg} \cdot \mathrm{l}^{-1}$ ), then deposited into a haemolysis tube by addition of $375 \mu \mathrm{l}$ of $\mathrm{BaP}$ solution and allowing $\mathrm{MeOH}$ solvent to evaporate. $3 \mathrm{ml}$ of concentrated culture filtrate previously obtained was added (at working concentrations: $1,2.5,5,7.5$ and $10 \mathrm{mg} \cdot \mathrm{ml}^{-1}$ ) into the haemolysis tube. Tubes were incubated in the dark for 24 hours. BaP fluorescence in filtrate solution was analyzed on a Perkin Elmer LS B50 spectrofluorimeter (excitation $295 \mathrm{~nm}$, emission $406 \mathrm{~nm}$, time integration $10 \mathrm{~s}$ [18]). Blanks were set up similarly in water with no filtrate added. The same experiment was also conducted at the concentration of $1 \mathrm{mg} \cdot \mathrm{ml}^{-1}$ in water with standard yeast mannan (Sigma, St Quentin Fallavier, France) and with hydroxypropyl- $\beta$ cyclodextrin (HPBCD) kindly donated from Roquette Frères (Lestrem, France) as references. For each treat- 
ment, triplicates were realized. Results were expressed as solubilization mean value \pm standard error for triplicates.

\section{Results}

\subsection{BaP Solubilization}

Figure 1 showed a linear relationship between culture filtrate concentration and $\mathrm{BaP}$ solubilization (measured by relative fluorescence intensity and expressed by calculus in $\mu \mathrm{g} \cdot \mathrm{l}^{-1}$ ) with a high correlation factor $\mathrm{R}^{2}=0.95$. For comparison, the same assessment of $\mathrm{BaP}$ solubilization was also conducted at one chosen concentration (1 $\mathrm{mg} \cdot \mathrm{ml}^{-1}$ ) in the presence of culture filtrate, water, standard yeast mannan and a well known cyclic oligosaccharide $\mathrm{HPBCD}$ as references. Concerning the $\mathrm{BaP}$ solubilization, the results indicated that, in our experimental conditions, the culture filtrate significantly increased the solubility of BaP. Indeed, solubility of BaP was 11.8 $\mu \mathrm{g} \cdot \mathrm{l}^{-1}$ with culture filtrate, a 4-fold increase compared to the $\mathrm{BaP}$ aqueous solubility of $2.7 \mu \mathrm{g} \cdot \mathrm{l}^{-1}$. This solubility enhancement was comparable to the one obtained with the yeast mannan. In the presence of a well known cyclic oligosaccharide HPBCD as reference, the BaP solubilization was about $28.4 \mu \mathrm{g} \cdot \mathrm{l}^{-1}$ (Table 1).

\subsection{Preparation and Analysis of the Culture Filtrate from Fusarium solani}

The culture filtrate was prepared from the culture me-

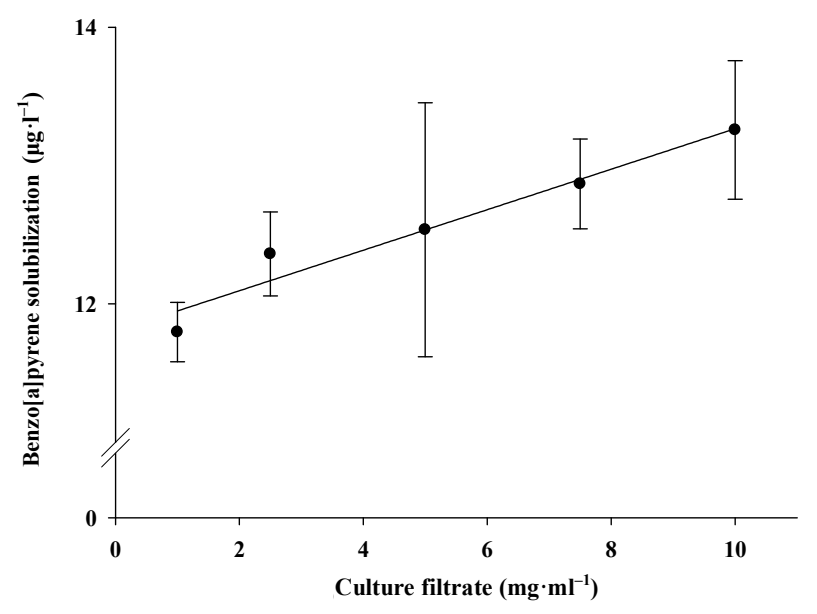

Figure 1. Relationship between culture filtrate concentration and BaP solubilization.

Table 1. Effect of tested compounds (at $1 \mathrm{mg} \cdot \mathrm{ml}^{-1}$ ) on benzo [a]pyrene solubilization.

\begin{tabular}{cc}
\hline Compound & BaP solubilization $\left[\mu \mathrm{g} \cdot \mathrm{l}^{-\mathbf{1}}\right]$ \\
\hline Water & $2.8 \pm 0.3$ \\
Culture filtrate & $11.8 \pm 0.5$ \\
Yeast mannan & $9.4 \pm 0.3$ \\
HPBCD & $28.4 \pm 0.6$ \\
\hline
\end{tabular}

dium after several filtration steps, dialysis and lyophilization. As assessed by colorimetric tests, the culture filtrate contained approximately $(\mathrm{w} / \mathrm{w}): 50 \%$ of total carbohydrate, $6.5 \%$ of uronic acid and $6 \%$ protein when respectively Glc, GlcA and BSA were used as standards.

Upon gel-filtration chromatography, the culture filtrate gave the main fraction which eluted at the void volume on a Sephadex G-50 column, and as a broad peak with $\mathrm{K}_{\mathrm{av}} \sim 0.4-0.75$ on Sepharose S-200. In both cases, protein and carbohydrate eluted simultaneously (data not shown) indicating that the major component of the culture filtrate was a glycoprotein.

The preparation was analyzed by SDS-PAGE with the periodate-silver staining, enhanced with alcian blue [17]. It showed a heterogeneous pattern with the major bands around $15-20 \mathrm{kDa}$ and other smaller bands ranging from 30 to $150 \mathrm{kDa}$ (Figure 2). On anion-exchange-column, the preparation eluted as a single sharp peak with simultaneous elution of total carbohydrate, protein and uronic acid at a $\mathrm{NaCl}$ concentration of $\sim 0.15 \mathrm{M}$ (Figure 3). This could indicate that despite the MW heterogeneity, the glycoprotein preparation was homogeneous in charge.

\subsection{Preparation and Structural Elucidation of the Polysaccharide}

${ }^{1} \mathrm{H}$ NMR spectrum of the sample contained two intense anomeric signals and several anomeric signals of smaller

12

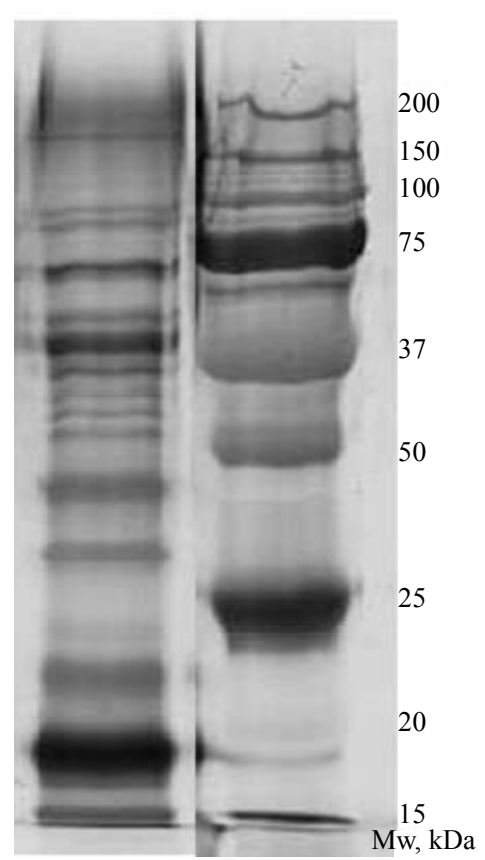

Figure 2. SDS-PAGE profile of the Fusarium solani culture filtrate (lane 1) along with the Precision plus protein standards (Bio-Rad). The gel was stained with alcian blue followed by periodate oxidation-silver staining. 


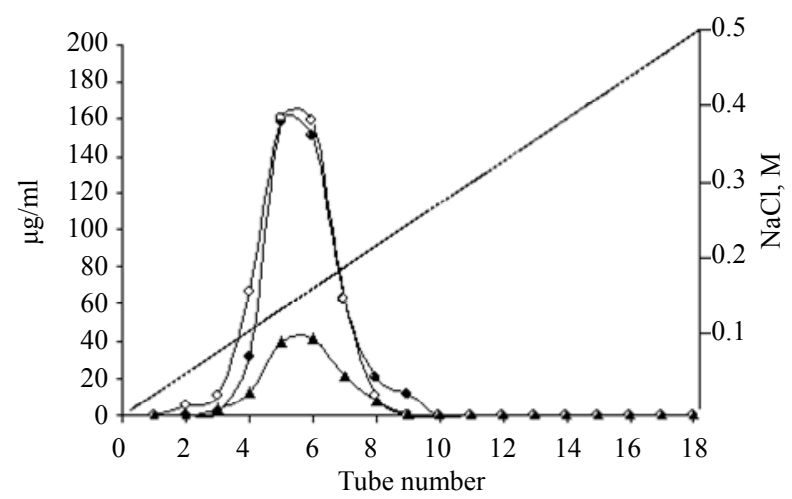

Figure 3. Elution profile of the Fusarium solani culture filtrate on an anion-exchange $Q-$ Sepharose fast flow column, eluted with 0 - $0.5 \mathrm{M}$ gradient $\mathrm{NaCl}$. Aliquots of each fraction were assayed for total sugars $(\bullet)$, protein $(\circ)$ and uronic acid $(\Delta)$ and expressed in $\mu \mathrm{g} \mathrm{ml}^{-1}$ of Glc, BSA and GlcA, accordingly.

intensity. Wobbling baseline and broad signals at 1 - 3 ppm indicated the presence of protein. Attempts to purify the major component by gel and anion exchange chromatography were not successful (data not shown), indicating that protein and carbohydrate moieties could be covalently linked. Sample was treated with proteinase K and products were separated by gel chromatography on Sephadex G-50. Polysaccharide containing fractions, eluted close to void volume, were collected and analyzed by composition analysis, methylation analysis, and 1- and 2D-NMR techniques.

Monosaccharide composition analysis led to identification of mannose (Man), glucose (Glc) and galactose (Gal) as main components in an approximate molar ratio of 1.5: 0.8: 1 and small amount of glucosamine (GlcN).

2D NMR spectra (DQCOSY, TOCSY, NOESY, ${ }^{1} \mathrm{H}^{-13} \mathrm{C}$ HSQC and HMBC, ${ }^{1} \mathrm{H}^{-31} \mathrm{P}$ HMQC) were recorded and interpreted. Two major sugar spin systems, $\mathbf{A}$ and $\mathbf{B}$, were identified (Figure 4). Residue $\mathbf{A}$ had ${ }^{13} \mathrm{C}$ NMR signals in the low field region (Table 2), which indicated furanoside form. Comparison of the ${ }^{13} \mathrm{C}$ chemical shifts with known values [19] indicated that it had $\beta$-galacto-configuration, and it was therefore identified as a $\beta$-galactofuranose. Residue $\mathbf{B}$ was identified as a $\alpha$ glucopyranose based on the characteristic vicinal proton coupling constants.

The linkages between sugars were identified as $\mathbf{A} 1 \rightarrow$ $\mathbf{A} 6$ and $\mathbf{B} 1 \rightarrow \mathbf{A} 2$ on the basis of NOE correlations: A1:A6, B1:A2, and confirmed by observation of HMBC cross peaks A H-1:A C-6; B H-1:A C-2. Thus, the major carbohydrate corresponded to a linear chain of $\beta-(1,6)$ linked Gal $f$ residues to which Glc $p$ is attached via $\alpha-(1,2)$ linkage as side chains (Figure 5).

The variant of $\alpha$-Glc (B' on Figure 4) also had NOE from $\mathrm{H}-1$ to the $\mathrm{A}-\mathrm{H}-2$, and strongly shifted $\mathrm{H}-4$ signal at $4.22 \mathrm{ppm}$. This was due to phosphorylation of its $\mathrm{O}-4$; $\mathrm{H}-4$ gave ${ }^{1} \mathrm{H}-{ }^{31} \mathrm{P}$ correlation $\left({ }^{31} \mathrm{P}\right.$ signal at $\left.2.02 \mathrm{ppm}\right)$. Minor signals in the spectra were identified as belonging

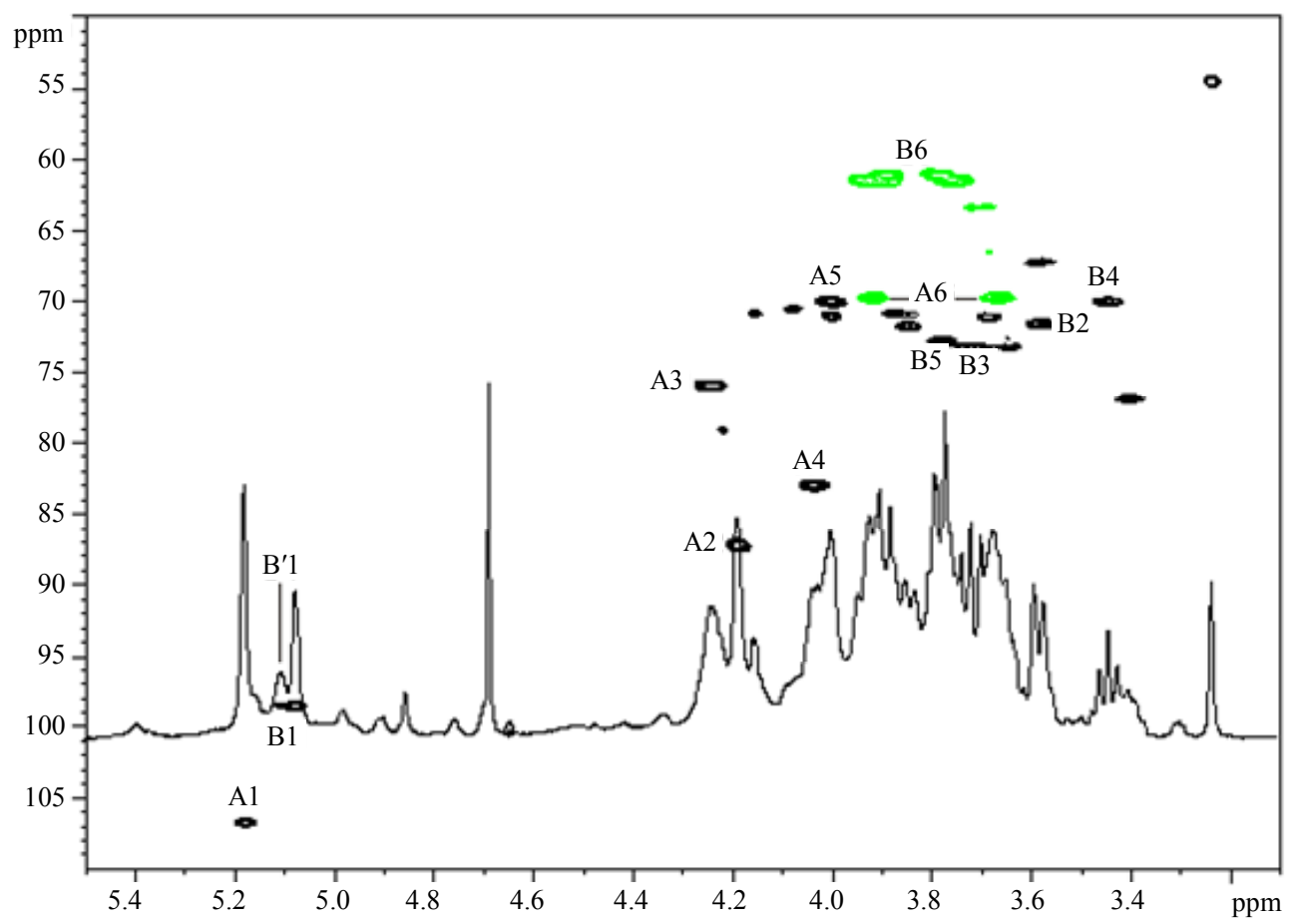

Figure 4. ${ }^{1} \mathrm{H}-{ }^{13} \mathrm{C}$ HSQC spectrum of the main carbohydrate, obtained after digestion of Fusarium solani culture filtrate with proteinase $\mathrm{K}$. Unlabeled signals belong to mannan. 
Table 2. ${ }^{1} \mathrm{H}$ and ${ }^{13} \mathrm{C}$ chemical shifts of the polysaccharide isolated from Fusarium solani culture filtrate following proteinase K treatment.

\begin{tabular}{ccccccccc}
\hline Unit & Atom & 1 & 2 & 3 & 4 & 5 & $6 \mathrm{a} / 6 \mathrm{~b}$ \\
\hline$\beta$-Gal $f \mathbf{A}$ & ${ }^{1} \mathrm{H}$ & 5.18 & 4.17 & 4.24 & 4.03 & 4.00 & $3.66 / 3.91$ \\
& ${ }^{13} \mathrm{C}$ & 106.8 & 87.1 & 75.9 & 82.9 & 70.0 & 69.7 \\
$\alpha$-Glc B & ${ }^{1} \mathrm{H}$ & 5.08 & 3.58 & 3.71 & 3.44 & 3.78 & $3.78 / 3.89$ \\
& ${ }^{13} \mathrm{C}$ & 98.4 & 71.6 & 73.2 & 70.0 & 72.8 & 61.1 \\
$\alpha$-Glc B & ${ }^{1} \mathrm{H}$ & 5.10 & 3.68 & 3.85 & 4.20 & 3.78 \\
& ${ }^{13} \mathrm{C}$ & 98.4 & 71.2 & 71.8 & 71.9 & 73.7 \\
\hline
\end{tabular}

$$
\begin{gathered}
\text { A } \\
{[-6)-\beta \text {-Galf-(1- ] }} \\
\underset{\text { B-Glc } p-(1-2)}{\text { B }}
\end{gathered}
$$

Figure 5. Suggested schematic structure of the main carbohydrate chain of the glycoprotein of Fusarium solani culture filtrate.

to a $\alpha$ - and $\beta$-mannose (data not shown). In addition, NMR spectra of all fractions contained a sharp peak at $3.25 / 54 \mathrm{ppm}$, which was higher in lower molecular mass fractions, and thus did not seem to belong to the main polysaccharide chain structure.

Methylation analysis afforded terminal glucose and 2,6-substituted galactofuranose, in agreement with the proposed structure. Additionally, peaks of 2- and 2,6substituted mannose were observed.

\section{Discussion}

In the present work, we prepared an extracellular extract from a strain of Fusarium solani previously isolated from petroleum-contaminated soil and showed that this preparation was able to solubilize a model organic pollutant $\mathrm{BaP}$. We present evidence that the major part of the extract contains an acidic glycoprotein, heterogeneous in size and containing Man, Glc, Gal and uronic acid. We showed that the major carbohydrate chain of the glycoprotein corresponded to a linear chain of $\beta$ - $(1,6)$-linked Galf residues, to which Glc $p$ is attached via $\alpha-(1,2)-$ linkage as side chains.

Knowledge on extracellular and cell-wall polysaccharides from Fusarium spp. and in particular in Fusarium solani is quite limited. Siddiqui and Adams were first to report the presence of an extracellular galactofuranosecontaining glycoprotein in Gibberella fujikuroi (Fusarium moniliforme) [20]; only few structural elements were then presented. To our knowledge, mycelium glycoproteins of only one Fusarium sp., designated M7-1, were elucidated in details [21-23]. Fusarium sp. M7-1 was found to produce acidic polysaccharides as components of the cell wall, and these polysaccharides were O-glycosidically linked to a protein moiety. The main structure of the polysaccharide consisted of a linear chain of $\beta$-(1,6)-linked Gal $f$ residues with various substitutions. Other minor oligosaccharide chains, released from the glycoprotein by mild alkaline treatment, were also characterized. They were composed mainly of Man residues with $\alpha$-(1,2)-linkages but also contained GlcNAc, Rha, Man-6-phosphate [24], Man-6-phosphoethanolamine [21], and Man-6-phosphocholine [25]. The same authors described the production of extracellular acidic glycoproteins by several Fusarium species, and characterized the structure of a glycoprotein from $F$. oxysporum. Similarly to Fusarium sp. M7-1, the sugar moiety of the glycopeptide contained a linear chain of $\beta$ - $(1,6)$-linked Gal $f$ residues with short side chains containing Glc, GlcA and Man [26]. Da Silva, Ribeiro, Sassaki, Gorin and BarretoBergter [27] analyzed the glycopeptides from mycelia of $F$. oxysporum using partial hydrolysis, methylation analysis and NMR. They concluded that $\beta$-Gal $f$ were substituted at O-6 with terminal $\beta$-Man residues.

Most of studies of polysaccharides of Fusarium and related species were aimed at the research of taxonomic and phylogenetic markers, and were often limited to monosaccharide composition and linkage type analysis of alkali-extractable water-soluble cell wall polysaccharides [28]. Ahrazem et al. [29] performed such analysis of several Fusarium and Gibberella species, but detailed chemical structures of these polysaccharides were not presented.

We further studied the properties of the concentrated fungal filtrate for $\mathrm{BaP}$ solubilization, a prerequisite to permit its incorporation into fungal cells which is one of the most limiting factors for BaP degradation. The concentrated fungal filtrate clearly showed a capacity to solubilize $\mathrm{BaP}$ similar to the yeast mannan standard (4-fold increase in comparison with the BaP aqueous solubility). We hypothesized that the enhancement of BaP solubilization could be partially due to the Fusarium solani extracellular glycoprotein and more particularly to 
its carbohydrate part. Indeed, some other carbohydrate compounds are well known to enhance aqueous solubility of organic molecules. Thus, cyclic oligosaccharides cyclodextrins possess apolar cavities which enable them to form inclusion complexes with hydrophobic molecules $[18,30]$. We have recently shown by molecular modelling that the polysaccharide amylopectin present in starch also presented several hydrophobic sites suitable for BAP complexation [31]. Glycoproteins could play a role of solubilizing compounds, possibly due to their amphiphilic nature. Masuoka and Hazen [32] demonstrated a relationship between modifications in the acid-labile $\beta$-1,2-oligomannoside chain of a cell wall $N$-glycosylated protein and the cell surface hydrophicity status in Candida albicans, indicating the effect of fine structural differences in the carbohydrate part of a glycoprotein on its hydrophobic/hydrophilic properties. At last, a bioemulsifier liposan produced by Candida lipolytica was characterized as a glycoprotein with its carbohydrate moiety presenting a similar composition to that of Fusarium solani [33].

Fungal heteromannans are well known as glycosidic moieties of fungal wall glycopeptides and glycoproteins [28]. As shown by immunofluorescence for Fusarium javanicum, they are located in the surface of fungal walls [29]. Most studies on these polysaccharides were conducted for searching taxonomical and phylogenetical markers; and the classical extraction process by alkali treatments hydrolyses the linkage between the protein and glycosidic moieties. Our findings showing the capacity of an extracellular glycoprotein from an important soil fungus $F$. solani to solubilize a model PAH BaP point out another important role that can be played by these molecules: their potential involvement in microbial bioavaibility of PAH, an important step in PAH biodegradation.

\section{Conclusion}

To summarize, our results show that the concentrated filtrate produced by Fusarium solani stimulated BaP solubilization. The glycoprotein present in this filtrate should probably be involved in this enhancement. The chemical structure of its main glycosidic chain was established. Further research should be conducted in order to precise the role of protein and carbohydrate parts of the glycoprotein in the solubilization and uptake of $\mathrm{BaP}$ by this strain of $F$. solani. Our findings point out the potential role of fungal glycoproteins in microbial degradation of PAH.

\section{REFERENCES}

[1] A. Dipple, "Polynuclear Aromatic Carcinogens," In: C. E. Searle, Ed., Chemical Carcinogens, ACS Monograph
Series 3, American Chemical Society, Washington DC, 1976, pp. 245-314.

[2] C. E. Cerniglia, "Biodegradation of Polycyclic Aromatic Hydrocarbons," Biodegradation, Vol. 3, No. 2-3, 1992, pp. 351-368. doi:10.1007/BF00129093

[3] C. Rafin, O. Potin, E. Veignie, A. Lounes-Hadj Sahraoui and M. Sancholle, "Degradation of Benzo[a]Pyrene as Sole Carbon Source by a Non White Rot Fungus, Fusarium solani," Polycyclic Aromatic Compounds, Vol. 21, No. 1-4, 2000, pp. 311-329. doi:10.1080/10406630008028542

[4] O. Potin, C. Rafin and E. Veignie, "Bioremediation of an Aged Polycyclic Aromatic Hydrocarbons (PAHs)-Contaminated Soil by Filamentous Fungi Isolated from the Soil," International Biodeterioration \& Biodegradation, Vol. 54, No. 1, 2004, pp. 45-52. doi:10.1016/j.ibiod.2004.01.003

[5] O. Potin, E. Veignie and C. Rafin, "Biodegradation of Polycyclic Aromatic Hydrocarbons (PAHs) by Cladosporium sphaerospermum Isolated from an Aged PAH Contaminated Soil," FEMS Microbiology Ecology, Vol. 51, No. 1, 2004, pp. 71-78.

doi:10.1016/j.femsec.2004.07.013

[6] Y. R. Wu, T. T. He, J. S. Lun, K. Maskaoui, T. W. Huang and $\mathrm{Z}$. Hu, "Removal of Benzo[a]Pyrene by a Fungus Aspergillus sp. BAP14," World Journal of Microbiology and Biotechnology, Vol. 25, No. 8, 2009, pp. 1395-1401. doi:10.1007/s11274-009-0026-2

[7] E. Veignie, C. Rafin, P. Woisel, A. L.-H. Sahraoui and F. Cazier, "Metabolization of the Polycyclic Aromatic Hydrocarbon Benzo(a)Pyrene by a Non-White Rot Fungus (Fusarium solani) in a Batch Reactor," Polycyclic Aromatic Compounds, Vol. 22, No. 1, 2002, pp. 87-97. doi:10.1080/10406630210372

[8] C. Rafin, E. Veignie, P. Woisel, F. Cazier and G. Surpateanu, "New Potential of a Deuteromycete Fungus $\mathrm{Fu}$ sarium solani in Benzo[a]Pyrene Degradation: An EcoPhysiological Hypothesis?" In: M. P. Glazer, Ed., New Frontiers in Environmental Research, Nova Science Publishers, Inc., New York, 2006, pp. 165-179.

[9] J. J. Cooney, C. Siporin and R. A. Smucker, "Physiological and Cytological Responses to Hydrocarbons by the Hydrocarbon-Using Fungus Cladosporium resinae," Botanica Marina, Vol. 23, 1980, pp. 227-232.

[10] O. Kappeli, P. Walther, M. Mueller and A. Fiechter, "Structure of the Cell Surface of the Yeast Candida tropicalis and Its Relation to Hydrocarbon Transport," Archives of Microbiology, Vol. 138, No. 4, 1984, pp. 279282. doi:10.1007/BF00410890

[11] Y. Deng, Y. Zhang, A. E. L. Hesham, R. Liu and M. Yang, "Cell Surface Properties of Five Polycyclic Aromatic Compound Degrading Yeast Strains," Applied Microbiology and Biotechnology, Vol. 86, No. 6, 2010, pp. 1933-1939. doi:10.1007/s00253-010-2477-7

[12] N. D. Lindley and M. T. Heydeman, "Uptake of Vapour Phase $\left[{ }^{14} \mathrm{C}\right]$ Dodecane by Whole Mycelia of Cladosporium resinae," Journal of General Microbiology, Vol. 129, No. 7, 1983, pp. 2301-2305.

[13] I. Ciucanu and F. Kerek, “A Simple and Rapid Method 
for the Permethylation of Carbohydrates," Carbohydrate Research, Vol. 131, No.2, 1984, pp. 209-217. doi:10.1016/0008-6215(84)85242-8

[14] M. Dubois, K. Gilles, J. K. Hamilton, P. A. Rebers and F. Smith, "A Colorimetric Method for the Determination of Sugars," Nature, Vol. 168, No. 4265, 1951, p. 167. doi:10.1038/168167a0

[15] N. Blumenkrantz and G. Asboe-Hansen, "New Method for Quantitative Determination of Uronic Acids," Analytical Biochemistry, Vol. 54, No. 2, 1973, pp. 484-489. doi:10.1016/0003-2697(73)90377-1

[16] U. K. Laemmli, "Cleavage of Structural Proteins during the Assembly of the Head of Bacteriophage T4," Nature, Vol. 227, No. 5259, 1970, pp. 680-685. doi: $10.1038 / 227680 \mathrm{a} 0$

[17] B. L. Reuhs, D. P. Geller, J. S. Kim, J. E. Fox, V. S. Kolli and S. G. Pueppke, "Sinorhizobium fredii and Sinorhizobium meliloti Produce Structurally Conserved Lipopolysaccharides and Strain-Specific K Antigens," Applied Microbiology and Biotechnology, Vol. 64, No. 12, 1998, pp. 4930-4938.

[18] E. Veignie, C. Rafin, D. Landy, S. Fourmentin and G. Surpateanu, "Fenton Degradation Assisted by Cyclodextrins of a High Molecular Weight Polycyclic Aromatic Hydrocarbon Benzo[a]Pyrene," Journal of Hazardous Materials, Vol. 168, No. 2-3, 2009, pp. 1296-1301. doi:10.1016/j.jhazmat.2009.03.012

[19] K. Bock and C. Pedersen, "Carbon-13 Nuclear Magnetic Resonance Spectroscopy of Monosaccharides," Advances in Carbohydrate Chemistry \& Biochemistry, Vol. 41, 1983, pp. 27-66. doi:10.1016/S0065-2318(08)60055-4

[20] I. R. Siddiqui and G. A. Adams, "An Extracellular Polysaccharide from Gibberella fujikuroi (Fusarium moniliforme)," Canadian Journal of Chemistry, Vol. 39, No. 8, 1961, pp. 1683-1694. doi:10.1139/v61-216

[21] T. Jikibara, K. Tada, K. Takegawa and S. Iwahara, "Studies on the Uronic Acid-Containing Glycoproteins of Fusarium sp. M7-1: II. The Primary Structures of the Low Molecular Weight Carbohydrate Chains of the Glycoproteins," Journal of Biochemistry, Vol. 111, No. 2, 1992, pp. 230-235.

[22] T. Jikibara, K. Takegawa and S. Iwahara, "Studies on the Uronic Acid-Containing Glycoproteins of Fusarium sp. M7-1: I. Isolation and Some Properties of the Glycoproteins," Journal of Biochemistry, Vol. 111, No. 2, 1992, pp. 225-229.

[23] T. Jikibara, K. Takegawa and S. Iwahara, "Studies on the Uronic Acid-Containing Glycoproteins of Fusarium sp. M7-1: III. The Primary Structures of the Acidic Polysaccharides of the Glycoproteins," Journal of Biochemistry, Vol. 111, No. 2, 1992, pp. 236-243.

[24] S. Iwahara, N. Suemori, N. Ramli and K. Takegawa,
"Isolation and Identification of Novel Acidic Oligosaccharides Derived from Glycoproteins of Fusarium sp. M71," Bioscience, Biotechnology and Biochemistry, Vol. 59, No. 6, 1995, pp. 1082-1085. doi:10.1271/bbb.59.1082

[25] S. Iwahara, N. Suemori and K. Takegawa, "Isolation and Identification of a Choline-Linked Mannobiose in the Glycoproteins of Fusarium sp. M7-1," Bioscience, Biotechnology and Biochemistry, Vol. 60, No. 2, 1996, pp. 349-350. doi: $10.1271 / \mathrm{bbb} .60 .349$

[26] K. Takegawa, K. Satoh, N. Ramli, T. Jikibara and S. Iwahara, "Production and Characterization of Extracellular Uronic Acid-Containing Glycoproteins from Fusarium oxysporum," Journal of Fermentation and Bioengineering, Vol. 83, No. 2, 1997, pp. 197-200. doi:10.1016/S0922-338X(97)83583-0

[27] R. B. Da Silva, G. L. Ribeiro, G. L. Sassaki, P. A. J. Gorin and E. Barreto-Bergter, "Uronic Acid-Containing Glycopeptides from Fusarium oxysporum: Possible Significance as Chemotypes," Carbohydrate Polymers, Vol. 60, No. 4, 2005, pp. 449-455. doi:10.1016/j.carbpol.2005.02.021

[28] J. A. Leal, A. Prieto, M. Bernabe and D. L. Hawksworth, "An Assessment of Fungal Wall Heteromannans as a Phylogenetically Informative Character in Ascomycetes," FEMS Microbiology Review, Vol. 34, No. 6, 2010, pp. 986-1014.

[29] O. Ahrazem, B. Gomez-Miranda, A. Prieto, I. Barasoaìn, M. Bernabe and J. A. Leal, "An Acidic Water-Soluble Polysaccharide: A Chemotaxonomix Marker for Fusarium and Gibberella," Mycological Research, Vol. 104, No. 5, 2000, pp. 603-610. doi:10.1017/S0953756299001550

[30] J. Szejtli, "Introduction and General Overview of Cyclodextrin Chemistry," Chemical Reviews, Vol. 98, No. 5, 1998, pp. 1743-1753. doi:10.1021/cr970022c

[31] A. M. Rosu, E. Veignie, G. Surpateanu, G. Brabie, D. N. Miron and C. Rafin, "Synthesis and Evaluation of Hydroxypropylated Potato Starch as Polymeric Support for Benzo[a]Pyrene Degradation by Fenton Reaction," Carbohydrate Polymers, Vol. 83, No. 4, 2011, pp. 1486-1491. doi:10.1016/j.carbpol.2010.09.059

[32] J. Masuoka and K. C. Hazen, "Cell Wall Mannan and Cell Surface Hydrophobicity in Candida albicans Serotype A and B Strains," Infection and Immunity, Vol. 72, No. 11, 2004, pp. 6230-6236. doi:10.1128/IAI.72.11.6230-6236.2004

[33] M. C. Cirigliano and G. M. Carman, "Purification and Characterization of Liposan, a Bioemulsifier from Candida lipolytica," Applied Microbiology and Biotechnology, Vol. 50, No 4, 1985, pp. 846-850. 